\title{
Corrigendum
}

Dennis R Young*

\section{Corrigendum to: Editor's Note for Issue 8(1)}

DOI $10.1515 / \mathrm{npf}-2017-5100$

Corrigendum to: Dennis Young. January 2017. Editor's Note for Issue 8(1). Nonprofit Policy Forum. Volume 8, Issue 1, pages 1-2. (DOI 10.1515/npf-2017-0011):

I regret having inadvertently omitted Michael Ford's name as co-author of the article "Entry Barriers and Nonprofit Founding Rates" in my Editor's Note for Issue 8(1). The omission has been corrected.

Dennis Young

*Corresponding author: Dennis R Young, Cleveland State University, Cleveland, OH 44115, USA, E-mail: dennisryoung@gsu.edu 